\title{
COMMENTARY
}

\section{Actions and re-actions of civic society and Patients Advocacy Groups across Europe during Covid-19 pandemic: Sharing good practices for more resilient Health Care Systems}

\author{
Mariano Votta $^{1^{*}}$ Bianca Ferraiolo $^{2}$ \\ ${ }^{1}$ Active Citizenship Network, c/o Cittadinazattiva APS, Via Cereate 6, 00183 Rome, Italy \\ ${ }^{2}$ Representative Office to the EU and Active Citizenship Network, Cittadinanzattiva APS, 1000 Brussels, Belgium
}

\section{Check for updates}

Correspondence to: Mariano Votta, Active Citizenship Network, c/o Cittadinazattiva APS, Via Cereate 6, 00183 Rome, Italy;

E-mail: m.votta@cittadinanzattiva.it

Received: July 1, 2021;

Accepted: July 28, 2021;

Published: July 29, 2021

Citation: Votta M and Ferraiolo B. Actions and re actions of civic society and Patients Advocacy Groups across Europe during Covid-19 pandemic: Sharing good practices for more resilient Health Care Systems. Adv Health Behav, 2021, 4(1): 164-170. https://doi.org/10.25082/AHB.2021.01.002

Copyright: () 2021 Mariano Votta and Bianca Ferraiolo. This is an open access article distributed un der the terms of the Creative Commons Attribution License, which permits unrestricted use, distribution, and reproduction in any medium, provided the original author and source are credited.

\begin{abstract}
The recent pandemic seriously affected national health systems worldwide. The focus of the 2021 edition of the European Patients' Rights Day was on patient organizations' concrete reactions to it, offering answers to people and actions that should be put in place in order to have more resilient healthcare systems, starting from the 14 rights stated in the European Charter of Patients' Rights. From their experiences emerged the great reforming force of civic organizations and Patient Advocacy Groups, capable of responding promptly to new needs by managing services, building alliances, quickly signalling necessary normative or procedural changes, mobilizing resources (both human and economic), introducing and promoting practices from which it will not be necessary to go back when everything is over. We still perceive the urgent need to better address the consequences of the Covid-19 pandemic Evidence collected during the crisis show that Covid-19 has had a significant impact - for instance - on Non-Communicable Diseases. Indeed, oncological and chronic patients have been left almost alone for several months. Rather than recalling the impact of Covid, the 15th European Patients' Rights Day wanted to highlight actions and reactions that have civic \& patients' organizations as protagonists: actions realized despite the pandemic and reactions put in place to mitigate its impact.
\end{abstract}

Keywords: Patient Advocacy Groups, civic activism, patients' rights, resilience, healthcare systems, Covid-19

\section{Introduction}

On 5 \& 6 May, 2021 has been celebrated the XV European Patients' Rights Day (EPRD) [1], promoted by Active Citizenship Network (ACN) [2], the European branch of Cittadinanzattiva [3] - a civic organization which promotes citizens' activism for the protection of their own rights, maintaining the common good, and offering the support for people in vulnerable conditions. It focused on the importance of the engagement of citizen organizations and the multisectoral approach to take action on cross-border health threats, both actual and future and has been held during the Italian's Presidency of the G20 [4], just before the Global Health Summit organised in Rome on the 21st of May 2021 [5].

The multi-stakeholder conference, digitally realized due to the healthcare crisis, focused on showing and discussing good practices of citizen's engagement in health policies in this particular historical moment: a first day, dedicated to the health challenges faced by non-Covid patients and a second day, focused on the resilience of the Healthcare Systems and the national immunization plans.

Indeed, the current pandemic placed a huge strain on healthcare systems, worldwide it forced to adapt and sometimes innovate care management: what are the lessons learned? What has been done by the civic society and Patient Advocacy Groups (advocacy activities for chronic patients $\&$ therapeutic plans; for cancer patients \& Covid-19 patients; in preparing and supporting the Covid-19 vaccination landscape, without forgetting the routine immunization schedules and its gains; solidarity for vulnerable target groups; concrete support to General Practitioners and other HCPs; political proposals; local/national initiatives; civic monitoring, etc.) to face this difficult situation?

The Covid-19 pandemic has had a major impact on citizens' lives in several aspects. One of the most important has been the limited access to different health services and it is not acceptable 
to respond to the immediate needs of citizens facing Covid-19 pandemic simply by closing services. Alternative organizational solutions are therefore needed to guarantee continuity and quality and it is even more important, in this historical moment, to work to build a proper citizen and patient organizations engagement culture: knowing and spreading the good practices and the lessons learned during this Covid-19 health crisis.

The pandemic affected people's livelihoods, economies, international trade. It has added its burden onto other systemic problems, from climate change to inequality but it has also made one thing clear: we live in an era in which local problems swiftly become global challenges. This means that we can work together to recover from this crisis and seize the opportunity to build back better, learning from our shared experience and ensuring that efficient and innovative tools and technologies become the basis for a more resilient, sustainable, healthy growth.

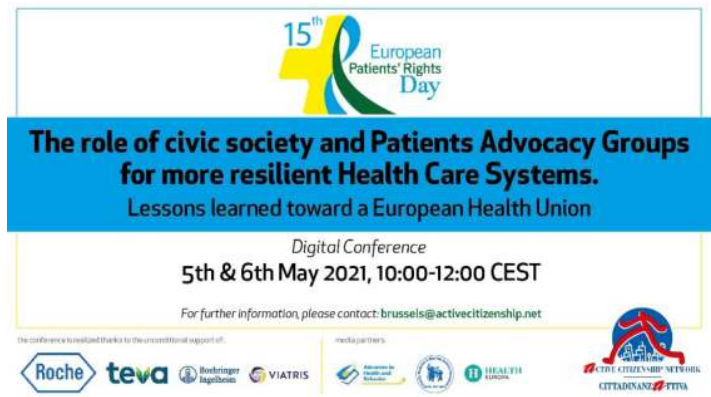

Figure 1 XV European Patients' Rights Day's save the date

As stated at the beginning of the Manifesto for a European Health Union [6]: "This will not be the last pandemic. There will also be many other threats to health, including the effects of climate change, antimicrobial resistance, and much else. We cannot continue with life as before. We have to safeguard our societies but in ways that are proportionate to the dangers which threaten them. We must welcome the clear statement by the European Commission President Dr Ursula von der Leyen in her September 2020 'State of the Union' [7] address, setting out the necessity to create a stronger European Health Union (EHU), building on recent efforts by the European Commission to take action on cross border health threats."

For this reason Active Citizenship Network used the European conference of the XV European Patients' Rights Day to value the good practices of citizen's engagement in health policies \& multi-stakeholder actions to tackle the pandemic for a future stronger European Health Union: concrete examples and experiences coming from different countries as action and reactions to and despite the pandemic.

\section{Origin \& value of European Patients' Rights Day}

In 2002, Active Citizenship Network (ACN) together with a group of European citizens organizations drafted the European Charter of Patients' Rights [8], which has been translated in 16 languages and includes the following 14 rights: the right to preventive measures; access care; information; consent; free choice; privacy and confidentiality; respect of patients' time; observance of quality standards; safety; innovation; avoidance of unnecessary suffering and pain; personalized treatment; to complain; to receive compensation. All these rights, based on the Charter of Fundamental Rights of the European Union [9], are crucial in matter of European citizens and healthcare services. The majority of these rights were also embodied within the Council conclusions on Common values and principles in EU Health Systems adopted in June $2006[10]$.

The reinforcement of these rights would become effective only with the cooperation and commitment of all healthcare stakeholders in every EU country. It is thus essential to increase awareness regarding the importance of patients' rights and everyone's responsibilities in guaranteeing their respect. The celebration of the European Patients' Rights Day every year in all the EU Member States would greatly contribute to this goal, as a common occasion to inform, discuss and take commitments to improve patients' rights in Europe and in each Member State. For this reason, ACN - together with citizens' and patients' organizations throughout Europe has taken the initiative to organize for the last fifteen years a European conference to celebrate the European Patients' Rights Day.

Now, the European Patients' Rights Day has become a regular annual event on the European [11] and national political agendas to inform, discuss and take commitments to improve patients' 


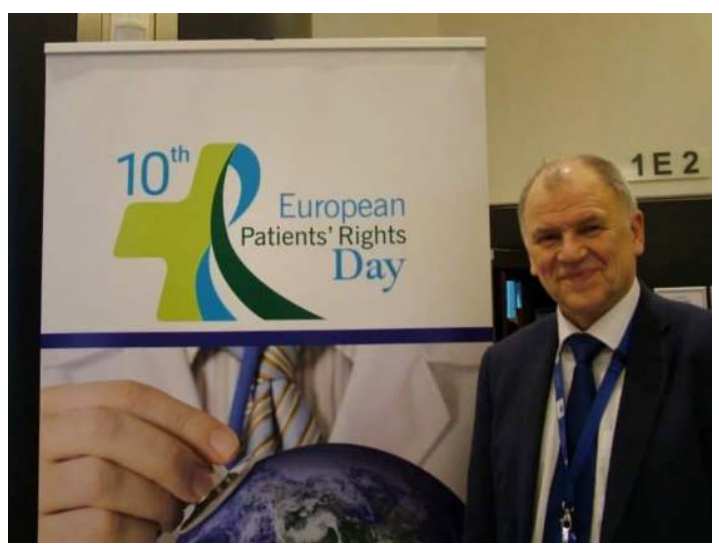

Figure 2 Vytenis Andriukaitis, former EU Commissioner for Health and Food Safety attending the 10th European Patients' Rights Day

rights in Europe and in each Member State. Every year, also thanks to the more than one hundred patient and civic associations of our network, the EPRD is celebrated in hundreds of cities and ways all around Europe [12], allowing civil society to fully enter policy making processes and achieve important objectives.

The first European Patients' Rights Day [13] was celebrated on 2007 in Brussels at the European Parliament, with over 180 delegates from 25 countries representing the interests of patients, public administration, policymakers, healthcare providers, legislators and industry stakeholders. The Head of Cabi-

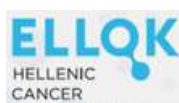
HELLENIC
CANCER CANCER net of the Commissioner, Mr. Philippe Brunet, opened the event and 23 MEPs from different political groups spoke of the importance of the existence of a European Patients' Rights Day. This was followed by two Parliament Resolutions [14] calling for the adoption of a European Charter of Patients' Rights [15] on the basis of existing Charters in the different Member States and of the work carried out by non-governmental organizations and recognizing "that there is a need to incorporate a common charter of patients' rights in the future Community framework in order to ensure such rights are exercised in practice across borders and in the home country". Then, the European Economic and Social Committee (EESC) approved an opinion on Patient's rights on September 26, 2007 [16] that "welcomes and acknowledges the European Charter of Patients' Rights, promoted by ACN since 2002”. Within the same opinion, the EESC calls on the European Commission to establish a European Patients' Rights Day.

\section{Concrete experience}

The aim of this paragraph is to provide enough details for each concrete experience presented by non-Covid 19 patients' national representatives during the 15th European Patients' Rights Day conference.

\subsection{Greece - Hellenic Cancer Federation (ELLOK) [17]}

Kathi Apostolidis, President of the Hellenic Cancer Federation (ELLOK) [18] and Board Member of the European Cancer Patient Coalition (ECPC) [19], explained the concrete initiatives that the Hellenic Cancer Federation put in place to help cancer patients during the Covid-19 pandemic.

The association aimed at:

(1) Highlighting and addressing the problems encountered by patients in cancer care and care;

(2) Developing collaborations with the government, the scientific community \& the private sector;

(3) Giving valid information to patients and citizens about the relation between Covid-19 and cancer;

(4) Training webinars addressed to ELLOK members and cancer patients to raise awareness and improve their digital skills.

All these challenges have been addressed by getting in contact with greek Ministry of Health and other institutional competent bodies, organizing meetings and analysing the attitude of 
cancer patients in the 1st and 2nd phase of the pandemic thanks to surveys towards Covid-19 $\&$ cancer prevention measures. Also, a free of charge patient's accommodation program for treatment has been put in place and a dedicated website has been realized.

\subsection{France - Ligue contre l'obésité [20]}

Alina Constantin, patients' council and international coordinator of the Ligue contre l'obésité [21] represented the work of her organization in favour of people living with obesity during the pandemic.

Among the actions realized for and with the patients there are:

(1) A dedicated help line for patients seeking information on health, psychological, social and legal issues, etc.

(2) Training activities for healthcare professionals and patients;

(3) A medical center specialized in obesity: "OBÉSANTÉ";

(4) The continuous involvement in the implementation of health national policies.

Also several political actions in favour of the patients were put in place as:

(1) The publication of recommendations addressed to people with obesity or having undergone bariatric surgery during the first period of confinement.

(2) Launch of a procedure in September 2020 before the Council of State in order to grant access to the partial unemployment and the 'isolation certificate' to people living with obesity. A favourable decision was obtained on the 15th of October 2020.

(3) French President Macron opened the vaccination schedule for people with obesity and other chronic diseases under 50 years old as part of vulnerable population (diabetes, HTA, asthma, etc.) after media campaigns and other activities advocating for this.

\subsection{Italy - Women Against Lung Cancer in Europe (WALCE) On- lus [22]}

Stefania Vallone, board member of the Women Against Lung Cancer in Europe (WALCE) [23] Onlus presented the European Program for Routine testing of Patients with Advanced lung cancer (EPROPA) [24] which is a support program promoted by WALCE and designed to offer equality of access to molecular testing and associated targeted drugs within clinical trials across Europe. EPROPA, through WALCE, involves Centres of Expertise in the treatment of lung cancer, Academia and Pharma Companies.

WALC's primary aims are to support people aff $\neg$ ected by lung cancer and their families and to promote educational programs for patients as well as awareness and primary prevention campaigns for the general public. The main goal is to generate a free-of-charge molecular screening platform for tumor characterization in order to increase the detection of oncogenic drivers (frequent or rare) in NSCLC (Non-Small-Cell Lung Cancer) patients. At the same time, patients access to biomarker-driven clinical trials id optimized.

The close collaboration with Academia gives the possibility to match molecular characteristics and ongoing biomarker-driven clinical trials and the opportunity to enter in a dedicated clinical trial. If the patient accepts to participate to this, EPROPA helps patients to reach the closest site where such study is available, covering the cost of journey and staying for both patient and one of his/her caregivers during the experimental treatment.

\subsection{Spain - Plataforma de Organizaciones de Pacientes [25]}

Ana Castellanos, Project Manager at Plataforma de Organizaciones de Pacientes [26], explained how the organization is working on reducing the impact of Covid-19 on patients, developing studies a running an epidemiological investigation on health care, labour impact and emotional impact of the pandemic.

The organization made a great effort to reinforce the protection of chronic patients' rights by: 1) strengthening their free legal clinic service to provide legal advice to patients and organisations 2) reviewing occupational safety protocols developed by the Spanish Ministry of Health to include special safety measures for people at high risk due to previous pathologies. 3) managing to offer home delivery of treatments provided in hospital pharmacies. 4) strengthening the collaboration and communication among patient organizations, the administration, the scientific community, health professionals and the rest of the health agents to deliver rigorous information 
and combat hoaxes, offering reliable and accurate information. 5) reinforcing communications by creating specific actions, content (such as press releases, articles, podcasts), organising online meetings and events.

They promoted also the inclusion of chronic patients as a priority group in the Spanish Covid-19 vaccination strategy, by analysing scientific evidence and conducting a study of the vaccination strategies of six European countries, holding meetings with the Spanish Ministry of Health, regional governments, parliamentary groups and other key stakeholders.

\subsection{Portugal - Associação de Apoio Domiciliário de Lares e Casas de Repouso de Idosos (ALI) [27]}

Among the many good practices collected, which unfortunately it was not possible to host during the XV European Patients' Rights Day, the initiative in favor of people living in residences deserves to be mentioned as elderly are without doubt among the most vulnerable categories of people which have been heavily affected by the pandemic. In particular, Active Citizenship Network thanks João Ferreira de Almeida, President of the Board of Associação de Apoio Domiciliário de Lares and Casas de Repouso de Idosos (ALI) for providing valuable information on the impact of Covid-19 on the residences for elderly in Portugal.

Despite some concrete measures adopted by both the residences for elderly and the government, it is clear that, being a vulnerable category, the most affected by the pandemic were the elderly. A survey conducted in Portugal on 329 residences recorded the following numbers, due to the isolation and suspension or reduction of family visits: worsening of mental or cognitive illness $-26.7 \%$, regression of locomotor capacity $-14.2 \%$, worsening of the general state of health $-4 \%$. Another very worrying consequence was the postponement of many consultations and medical examinations and surgeries because of the priority given to the pandemic. There are concrete data showing that patients, especially those who are affected by cancer and respiratory issues, are arriving at hospitals with the diseases at a very advanced stage and no more possibility of treatment.

In order to improve this situation, it is crucial to raise the level of healthcare practiced in residences, because the current level is unsatisfactory for the needs of the elderly. Moreover, given the enormous dimension of the problem that need to be solved, if each country is left to try to resolve them on its own and without having a combined European policy, it will be very difficult to achieve any good result.

\subsection{Ethic statement}

The authors have worked in full compliance with the Code of Conduct of Cittadinanzattiva APS [28].

\section{Discussion}

From the account of oncological and chronic patients during the pandemic, it emerged how they have been left almost alone for several months, a situation that jeopardized 20 years of prevention.

Hence, Active Citizenship Network drafted a Manifesto with 10 recommendations [29] already signed by 50 associations from 18 countries - addressed to the institutions to remark non-covid patients' unmet needs. Above all, to encourage forms of monitoring as "Follow the Money" to monitor together the funds of Recovery Plans that each European country is receiving and engage European citizens to improve health systems. There is the need to be heard because, as in any reconstruction, the involvement of a large number of active and aware social and civic actors is crucial. The other eights recommendations are: to monitor Covid-19 impact on non-Covid-19 patients; to urgently secure safe access to diagnostic, immunization, screening and treatments; to secure well-resourced healthcare systems post Covid-19; to support the Digital Healthcare transition; to affirm a life-course approach for chronic diseases prevention; to strengthen a 'One Health approach' to prevent future pandemic; to develop coordinated initiatives for the rights of patients living with multi co-morbidity; "Health for all EU citizens" must be placed at the heart of the Conference on the Future of Europe.

One of the main messages coming from the European Patients' Rights Day 2021 was that, in times of needed changes for more resilient healthcare systems, it is necessary to recognize the 
key role of Patients' Advocacy groups (PAGs), citizens' organizations involved in the field of healthcare and, more generally, of all the actors that promote health as a common good.

On the day that the Joint Declaration on the Conference on the Future of Europe was signed, the first results of the special Eurobarometer survey on the future of Europe were published. Among many other things, respondents were asked to choose what developments they want to see in Europe's future. Having comparable living standards (35\%) and a stronger solidarity among Member States (30\%) are the two developments most cited. Europeans also prioritise the development of a common health policy (25\%). And for the citizens of nine countries, including Italy, health risks are a major concern. At the end of April 2021, Member States defined their Recovery Plans, multi-year plans that will have a significant impact on future generations and all citizens, probably the main tools to guarantee more resilient Health Care Systems across Member States in the coming years. If the aim of the Recovery Plans is the recovery and resilience of each of the countries in which we live, these are unattainable without the involvement of citizens in the choices and proposals the Plans contain, as well as in the monitoring of the projects that will translate the Plans into concrete interventions. The Next Generation EU should be fully implemented, as this, among other indications, outlines - for the approval and implementation of each Recovery Plan - the need to involve social forces and the civil society. So far, this has occurred only in some countries and thus it is essential to ensure better transparency and participation in order to monitor the operational development of each Recovery Plan, being able also to compare, country by country, the actions undertaken in terms of citizen's health.

\section{Acknowledgements}

The European conference of the XV European Patients' Rights Day has been realized thanks to the unconditional support of F. Hoffmann-La Roche LTD, Teva Europe, Boehringer Ingelheim International $\mathrm{GmbH}$ and Viatris.

\section{References}

[1] The XV European Patients' Rights Day. http://www.activecitizenship.net/patients-rights/projects/382-european-patients-rights-day-2021

[2] Active Citizenship Network. http://www.activecitizenship.net/

[3] Cittadinanzattiva. https://www.cittadinanzattiva.it/chi-siamo/about-us

[4] The G20 https://www.g20.org/about-the-g20

[5] The Global Health Summit 2021. https://www.g20.org/the-global-health-summit-ended-with-the-signing-of-the-rome-declaration

[6] Manifesto for a European Health Union. https://europeanhealthunion.eu

[7] State of the Union Address by President von der Leyen at the European Parliament Plenary. https://ec.europa.eu/commission/presscorner/detail/en/SPEECH_20_1655

[8] The European Charter of Patients' Rights basis document. https://ec.europa.eu/health/ph_overview/co_operation/mobility/docs/health_services_co108_en.pdf

[9] The Charter of Fundamental Rights of the European Union. https://www.europarl.europa.eu/charter/pdf/text_en.pdf

[10] Council Conclusions on Common values and principles in European Union Health Systems. https://eur-lex.europa.eu/legal-content/EN/TXT/PDF/?uri=CELEX:52006XG0622(01)\&from=EN

[11] Some examples of the previous editions of the European Patients' Rights Day: 2013, 2014, 2017, 2018.

[12] Active Citizenship Network “International \& national celebrations for the European Patients' Rights Day".

http://www.activecitizenship.net/patients-rights/projects/247-international-national-initiatives-forthe-european-patients-rights-day

[13] The first European Patients' Rights Day. http://www.activecitizenship.net/patients-rights/projects/32-1st-european-patients-rights-day

[14] European Parliament resolution of 15 March 2007 on Community action on the provision of crossborder healthcare. http://www.europarl.europa.eu/doceo/document/TA-6-2007-0073_EN.html?redirect

[15] Active Citizenship Network "The European Charter of Patients' Rights". http://www.activecitizenship.net/charter-of-rights.html 
[16] Opinion of the European Economic and Social Committee on 'Patients' rights'. https://eur-lex.europa.eu/legal-content/EN/TXT/HTML/?uri=CELEX:52007IE1256\&from=HU

[17] The experience of the Hellenic Cancer Federation (ELLOK). http://www.activecitizenship.net/files/patients_rights/european-patients-rights-day-2021/Kathi-Ap ostolidis-EPRD2021-ELLOK.pdf

[18] The Hellenic Cancer Federation (ELLOK). https://ellok.org/\%CF\%80\%CE\%BF\%CE\%B9\%CE\%BF\%CE\%AF-\%CE\%B5\%CE\%AF\%CE\%B $\mathrm{C} \% \mathrm{CE} \% \mathrm{~B} 1 \% \mathrm{CF} \% 83 \% \mathrm{CF} \% 84 \% \mathrm{CE} \% \mathrm{~B} 5 /$ ?lang=en

[19] The European Cancer Patient Coalition. https://ecpc.org/

[20] The experience of the Ligue contre l'obésité. http://www.activecitizenship.net/files/patients_rights/european-patients-rights-day-2021/Alina-Co nstantin-Ligue-contre-1-obesite-France.pdf

[21] Ligue contre l'obésité. https://liguecontrelobesite.org/?gclid=CjwKCAjwwqaGBhBKEiwAMk-FtOVhgLtJL0MSz4ABb WjZ7oRPVumNBStxgKcCGhlIC9cPedOs0zCDRRoCjrQQAvD_BwE

[22] The experience of Women Against Lung Cancer in Europe (WALCE) Onlus. http://www.activecitizenship.net/files/patients_rights/european-patients-rights-day-2021/Stefania - Vallone-epropa-flyer-MD-EN-pages-(1).pdf

[23] Women Against Lung Cancer in Europe (WALCE) Onlus. https://www.womenagainstlungcancer.org/?lang=en

[24] the European Program for Routine testing of Patients with Advanced lung cancer (EPROPA). https://www.epropa.eu/en

[25] Experience of the Plataforma de Organizaciones de Pacientes. http://www.activecitizenship.net/files/patients_rights/european-patients-rights-day-2021/Ana-Cast ellanosPOP_Actions_Completo.pdf

[26] Plataforma de Organizaciones de Pacientes. https://www.plataformadepacientes.org

[27] Associação de Apoio Domiciliário de Lares and Casas de Repouso de Idosos (ALI). https://www.ali.pt

[28] Cittadinanzattiva APS, "Codice di Condotta".

http://www.cittadinanzattiva.it/files/corporate/istituzionale/documenti_identita/codice_condotta_ca pdf

[29] Addressing non-covid patients: COVID-19 lessons learned for more resilient Health Care Systems. 10 Concrete recommendations towards a European Health Union. http://www.activecitizenship.net/patients-rights/projects/387-addressing-non-covid-patients-covid -19-lessons-learned-for-more-resilient-health-care-systems.html 